\title{
O inimigo objetivo em distopias pós-11 de Setembro: uma análise de Holy Terror: Terror Sagrado e Jogos Vorazes
}

\author{
Objective Enemy in Post-9/11 Dystopias: An \\ Analysis of Holy Terror and The Hunger Games
}

\author{
Monique Heloísa de Souza ${ }^{1}$ \\ Murilo Ariel de Araujo Quevedo ${ }^{2}$
}

DOI: $10.19177 /$ memorare.v8e12021107-126

\begin{abstract}
Resumo: A literatura distópica da terceira onda é fortemente influenciada pelos eventos do 11 de Setembro de 2001. Todavia, diferentemente dos anteriores, os materiais que compõem a terceira onda da ficção científica são, em sua grande maioria, produtos de cultura de massa, protagonizados por jovens adultos. Para essa leitura, analisamos duas obras contemporâneas que apresentam as características da terceira onda da ficção científica. De um lado, a trilogia Jogos Vorazes, que se passa em um cenário distópico e é protagonizada por uma adolescente. De outro, o quadrinho de Frank Miller, Holy Terror, protagonizado por adultos em uma Nova Iorque alternativa no 11 de Setembro. As duas obras são unidas pelo conceito arendtiano do inimigo objetivo. No entanto, averiguamos que elas apresentam faces diferentes da teoria de Arendt (2013), de um inimigo que pode ser interno ou externo, mas que são potencializadas pela efervescência do nacionalismo estadunidense. Palavras-chave: Inimigo objetivo. Holy Terror. Jogos Vorazes.
\end{abstract}

\begin{abstract}
The dystopian literature of the third wave is heavily influenced by the September 11th attacks. However, differently from those which preceded it, the materials which constitute the third wave of science fiction are mostly mass culture products whose leading characters are young adults. In this paper, we analyze two contemporary works which present the characteristics of sci-fi third wave. On one hand, the Hunger Games trilogy, which takes place in a dystopian world and has a teenage girl as the leading character. On the other hand, Frank Miller's comic book Holy Terror, starring adult characters in an alternative New York on the September 11th, 2001. These two works are linked by the Arendtian concept of the objective enemy. Nevertheless, our examination revealed that these titles present different viewpoints on Arendt's theory (2013), of either an internal or external enemy, which are enhanced by the effervescence of the USA nationalism.

Keywords: Objective enemy. Holy Terror. The Hunger Games.
\end{abstract}

\footnotetext{
1 Bacharela em Jornalismo (UFSC). Mestranda em Literatura (UFSC). moniquehsouza@outlook.com

2 Licenciado em Letras - Português e Inglês (UFRGS), Especialista em Histórias em Quadrinhos (Faculdades EST). Mestrando em Literatura (UFSC). murilo.quevedo93@gmail.com
} 


\section{Introdução: utopia e distopia - contrapartes}

Considerando o futuro como espectro infinito, cada projeção é uma possibilidade, ou o fim de uma possibilidade; um caminho, ou o fim de um caminho. Nessa incontável gama de cenários, o mundo como o conhecemos não existe mais, e nos resta apenas especular o que ele pode se tornar. Se mantivermos esse passo, o que nos espera adiante: um mundo de sonho ou um mundo de catástrofe? ${ }^{3}$ E mais: quão distantes de fato estão essas realidades?

Um dos extremos desse espectro surge no início do século 16. Os relatos do viajante Rafael nos transportam para Utopia, uma ilha longínqua, isolada do território hostil que é o continente, "uma nação que supera quase todas as outras pela cultura e civilização" (MORE, 2004, p. 48). Em todas as frentes, Utopia é privilegiada: geografia, arquitetura, tecnologia, subsistência, defesa, organização política, distribuição de recursos. Ao mesmo tempo, é um não-lugar; uma possibilidade por enquanto não alcançada e talvez inalcançável.

Muito mais tangível e próxima é sua contraparte, a distopia, que nasceu da reação às ideias utópicas de Thomas More e daqueles que nele se inspiraram. Unindo dys (dor, tristeza, infelicidade) a topos, descobrimos que distopia é o lugar da dor. Obras distópicas expressam

[...] de forma contundente o espírito do tempo em que foram escritas, projetando sociedades que se localizam em mundos ou datas distantes das que seus escritores vivem, abordando de forma exagerada elementos da realidade para que se possa, ao sermos de certa forma deslocados, enxergar de maneira crítica a realidade que nos cerca. Imergindo nos elementos mais sombrios das sociedades, as distopias são alertas, críticas, e exercem um papel extremamente político (BARBOSA, 2017, p. 92).

Em outras palavras, a visão do autor de literatura distópica antecipa um cosmo catastrófico. Um texto distópico é um alerta: no cenário em que nos encontramos, essas temáticas são urgentes, a negligência é perigosa e um futuro nefasto nos espera.

Ao tratar da relação entre utopias e distopias, usamos a expressão contraparte de forma intencional. Inicialmente, porque um horizonte utópico fala tão legitimamente de um presente controverso quanto um horizonte distópico. Ademais, uma utopia para alguém pode ser uma distopia para outra pessoa. Ou seja, "elementos que eram vistos de forma positiva nos textos utópicos são vistos como os grandes causadores de alienação e dor nos textos distópicos" (BARBOSA, 2017, p. 31). Os dois conceitos são interdependentes: um sonho e um pesadelo que existem em função um do outro. Um sistema - social, econômico, político etc. - pode mudar, evoluir, regredir, desviar-se, distorcer-se; criar uma estrutura privilegiada não significa a capacidade de mantê-la assim indefinidamente. Ela pode se tornar algo completamente diferente da ideia original, com os mesmos problemas dos quais se quer fugir.

Na história desse subgênero da ficção científica, identificamos três ondas com picos de publicação que alcançaram números altíssimos de vendas - cada uma relacionada a um evento histórico que repercutiu na literatura. A primeira onda, inspirada nas tensões da Segunda Guerra

3 Cf. BUCK-MORSS (2018). 
Mundial. A segunda, surgida no ápice da Guerra Fria. Vamos, contudo, nos deter na terceira onda, que tem início após os ataques contra o World Trade Center, em 11 de setembro de 2001.

Independentemente do período e de suas singularidades, todas as obras dividem o mesmo pano de fundo: perda da liberdade de escolha, supressão da individualidade dos sujeitos em benefício de uma suposta coletividade, autonomia em relação ao próprio corpo, governos opressores, desconfiança do Estado e inconformismo com as estruturas hierárquicas de organização social. Se procurarmos um equivalente desse cenário fora das literaturas, é natural que esses picos tenham acontecido em momentos históricos marcados por grandes choques e longos períodos de terror (GOODREADS, 2012).

Quanto à terceira onda, diferencia-se das outras por alguns fatores. Enquanto grande parte da literatura distópica anterior é considerada clássica, tendo entrado para os cânones literários mundiais, a maioria das obras pós-11 de Setembro pertence à indústria cultural, muitas vezes nem categorizada como literatura, mas como entretenimento.

Além disso, as primeiras ondas eram um alerta geral às sociedades ocidentais de suas épocas: embora com exceções, havia um sentimento de que o terror totalitário não fazia distinções de idade, sexo, gênero, cor, sexualidade, classe ou religião. As pessoas eram afetadas em maior ou menor grau de acordo com essas características, sim, mas nem por isso escapavam da zona de violências reais e simbólicas em que estavam inseridas.

A literatura distópica da terceira onda, embora públicos diversos se rendam a seus aspectos populares, é evidentemente direcionada ao público jovem. Como explica Melissa Ames (2013), não são exatamente os eventos de 11 de setembro de 2001 os responsáveis pelos medos dos jovens de hoje (ou mesmo da época em que as novas distopias começaram a ser lançadas); muitos ainda eram crianças demais para entender a gravidade da situação. A potência com que autores de literatura distópica conseguiram alcançá-los se deve ao clima de temor disseminado por governos, mídia hegemônica e redes sociais após os ataques, gerando uma cultura de informação ininterrupta em que terrorismo e violência estão sempre presentes.

Nesse contexto, destacamos duas obras publicadas entre 2010 e 2012. As temáticas de ambas as produções dialogam com os eventos do 11 de Setembro e podem ser analisadas pela perspectiva do inimigo objetivo, conceito elaborado por Arendt (2013). No entanto, são as diferenças de formato, de viés e de público-alvo que justificam nossa escolha. Na literatura distópica juvenil, o adulto é, ao mesmo tempo, inimigo e espelho - aquele contra quem o adolescente precisa lutar para não se tornar exatamente como ele. Ou o mundo muda, ou quem muda é você: seus sonhos, seus desejos, seus afetos, suas ambições, tudo será sublimado em uma figura tão destruída e destrutiva como essa que você condena. Entre tantas obras de literatura distópica juvenil surgidas durante a terceira onda, esse é um mote especialmente destacado na trilogia Jogos Vorazes (COLLINS, 2010, 2011, 2012).

Como contraponto, apresentamos um quadrinho publicado em 2011 por Frank Miller, que tem como protagonista uma versão idealizada de masculinidade: um homem bruto e de musculatura 
hiperdesenvolvida, que atua em uma cidade fictícia como vigilante mascarado. Idealizam-se a ausência de sentimentos e a ideia de que homens devem resolver os problemas (pessoais e externos) à base de força e de violência. Percebe-se nele o adulto que os protagonistas adolescentes de outras distopias, destinadas a um público mais jovem, não querem se tornar. 0 sistema falhou com esse jovem, e ele se tornou justamente o adulto condenável, que não se permite sentir, que trabalha na manutenção do mesmo mecanismo que o criou. Para essa análise, traremos uma leitura de Holy Terror (2013). Seja no quadrinho de Miller, seja na trilogia de Collins, evocaremos o conceito do inimigo objetivo para tratarmos de ambos os objetos pertencentes à terceira onda da literatura distópica.

\section{0 inimigo objetivo, a sociedade norte-americana e o 11 de Setembro}

011 de Setembro é um marco, um limiar histórico, político e simbólico; setores inteiros da sociedade norte-americana, incluindo a sociedade civil, dividem o tempo em "antes do 11 de Setembro" e "depois do 11 de Setembro". As mudanças culturais de comportamento e de expectativa - reafirmadas pela TV e pelo cinema - estabelecem as duas eras como díspares (GURR, 2015).

0 medo disseminado tanto pelo governo quanto pela mídia se fundamenta em muitas causas, mas basta retirarmos a cortina da ameaça estrangeira para encontrarmos o que há por trás dela: vulnerabilidade - uma qualidade desde sempre reservada a outros países, a outros povos, a Outros. De repente, os Estados Unidos não eram mais intocáveis. A vaidade do american way of life se transformou em luto e terror. Esse estado de espírito precisava ser superado, tanto pela população quanto pelo governo, que não podia permitir que sua soberania fosse minada. Assim, de um lado, cidadãos reafirmavam seu patriotismo, ostentavam símbolos nacionais, principalmente a bandeira, e se submetiam à autoridade máxima do país.

O debate é identificado como dissidência, o que por sua vez é identificado como deslealdade. Existe um sentimento disseminado de que, nessa emergência nova e em aberto, não podemos nos dar ao "luxo" de nossas liberdades tradicionais. As pesquisas mostram que os "índices de popularidade" de Bush ultrapassam 90\% - um índice que se aproxima da popularidade dos líderes das ditaduras do antigo estilo soviético (SONTAG, 2008, p. 84-85).

Do outro lado, o governo faz o que resta: utiliza a vulnerabilidade a seu favor. Aproveita o pesar do mundo e segue com a rotina de sensibilização, ao mesmo tempo mostrando os dois lados dos Estados Unidos: o líder chocado e consternado com tamanho ato de brutalidade, mas enérgico o suficiente para responder à altura. Cria-se um novo movimento de expansão territorial, uma colonização militarizada empreendida pelos soldados estadunidenses em missões "civilizatórias" e "de paz".

Não foi a primeira vez que os Estados Unidos utilizaram a vulnerabilidade para reafirmar sua soberania. Buck-Morss (2018) identifica o modus operandi norte-americano de como um Estado-nação pode ser reconhecido como soberano na ordem mundial. 
O primeiro passo envolve a questão: o que é necessário para esse reconhecimento? 0 direito de declarar guerra, o uso da força física. Mas não qualquer uso - apenas o legítimo, considerado inevitável. Assim, segundo passo: o que é necessário para que o uso da força seja legítimo? Um inimigo contra o qual lutar, uma ameaça. Terceiro passo: se não existe inimigo, há a possibilidade de inventar um. Países do Oriente Médio, cartéis latino-americanos, categorias políticas de oposição (como socialismo ou comunismo), refugiados, grupos extremistas. 0 inimigo traz perigo, mas o principal perigo é que o inimigo deixe de existir.

Na verdade, a ideia é antiga - Rousseau já esboçava a figura do inimigo nacional, que tornaria a nação um todo indivisível, e Arendt o retoma para criar a categoria de "inimigo objetivo" - que descreve o ódio nazista aos judeus, aos poloneses, a alguns alemães.

0 conceito de "oponente objetivo", cuja identidade muda de acordo com as circunstâncias do momento - de sorte que, assim que uma categoria é liquidada, pode declarar-se guerra à outra -, corresponde exatamente à situação de fato reiterada muitas vezes pelos governantes totalitários, isto é, que o seu regime não é um governo no sentido tradicional, mas um movimento, cuja marcha constantemente esbarra contra novos obstáculos que têm de ser eliminados (ARENDT, 2013, p. 362).

Enquanto a história nos mostra a busca pela ameaça legitimadora exterior, vemos também um padrão de ameaças internas, em diversas configurações. Seja a individualidade de cada cidadão, seja a classe, a raça ou o gênero, ou mesmo a simples oposição a qualquer decisão do governo, teóricos e acadêmicos do tema concordam que uma nação pode encontrar esse inimigo dentro de suas fronteiras. Não importa de que lado da linha geográfica se encontra, mas sim sua disposição em assoprar a "ferida narcisista aberta" (BUTLER, 2006, p. 31) da vulnerabilidade nacional. Cortam-se relações com nações, órgãos institucionais, organizações, optando pela unilateralidade e pelo isolamento.

Temos, então, o palco preparado: uma nação que se manteve soberana criando inimigos; uma retaliação que expôs as rachaduras no muro que fortifica essa nação; a manipulação dessa vulnerabilidade para criar um estado permanente de medo, de modo a justificar a resposta violenta; a recuperação da soberania pela bestialidade. 0 que se instala a partir desse cenário é uma zona selvagem, um território de terror acima da lei. 0 Estado-nação dá a si mesmo o apanágio sobre as vidas dos inimigos e sobre as vidas de seus próprios cidadãos. É um terror que beira a psicose; é o uso do terror para combater o terror, criando o que se quer destruir (BENJAMIN, 2013; BUCK-MORSS, 2018).

Os governos que utilizam esse terror para controlar suas populações precisam "[...] encaixar cada um [de seus sujeitos] igualmente bem no papel de executor e no papel de vítima" (ARENDT, 1953, p. 315, tradução nossa).4 Nessa zona selvagem, uma pessoa não é culpada ou inocente; ela passa a ser culpada $e$ inocente. Os sempre presumidos inofensivos acabam obrigados a se corromper para sobreviver ao terror de Estado.

4 No original: "[...] to fit each of them equally well for the role of executioner and the role of victim". 


\subsection{Bestialidade e soberania}

Do que se trata a soberania que os Estados Unidos tentam manter às custas da criação de uma zona de terror simultaneamente interna e externa? Mbembe (2011, p. 21) denomina a soberania como o "direito de matar" - um poder ${ }^{5}$ que produz e invoca um estado de exceção e um inimigo ficcionalizado. Arendt (1999) adota o termo raison d'état (razão de Estado) para designar o direito que um governo tem de cometer atos criminosos para sobreviver, e não necessariamente contra oponentes externos. Crimes, esses, que acontecem em situações excepcionais, porque nenhuma entidade política tem o direito de dizer como um Estado-nação deve preservar sua existência, mas que podem se tornar a regra no caso de um governo cujas bases são atos criminosos em si.

Mas a combinação e ao mesmo tempo oposição de soberania e bestialidade, feita por Derrida (2008), vai além da política, da história e do campo jurídico quando explica o poder soberano por uma perspectiva fundada na divisão de gênero. $A$ besta. $O$ soberano. Um par em que - assim como a utopia e a distopia - uma metade não existe sem a outra. Um par animalizado de um lado e racional do outro. 0 soberano, principalmente em sua forma majestas, olha para a besta do alto - do alto de seu trono, de seu altar, de seu palanque, cercado por edifícios ainda maiores, grandes projeções fálicas que avultam sobre o solo onde se encontra a besta e sua terrenalidade.

E, concretamente, isso se traduz, na efetividade política da coisa, não apenas como um poder total do Estado sobre vida-morte, o direito de perdão, geração, nascimento, potência sexual como poder gerador e demográfico, mas também a altura da qual o Estado tem o poder de ver tudo, de ver o todo, tendo literalmente, potencialmente, um direito de inspeção sobre tudo (DERRIDA, 2008, p. 215, tradução nossa). ${ }^{6}$

A fluidez do par besta-soberano, entretanto, caracteriza o estado dessa. O soberano também se torna besta quando encara o inimigo. No caso dos Estados Unidos, que precisam se proteger do que Derrida criticamente chama de rogue states, o inimigo deve ser ameaçado pela imagem bestializada da nação - um adversário capaz de tudo, de perder o controle e a racionalidade, de ser louco e animal. Essa soberania animalizada não é natural; ela é artificial, mecânica, protética, atrelada à militarização e ao armamentismo tecnológicos.

Dos terrores inspirados pela soberania, o mais terrível é aquele que, com pretensões paradoxalmente humanitárias $e$ bélicas, desumaniza o Outro; aquele que os trata como bestas, quando na verdade a parte bestializada é o próprio soberano.

\subsection{Nacionalismo e militarismo}

Dessa forma, o militarismo espetacularizado é uma alavanca para o nacionalismo, afirma Anderson (2008). Assim como a educação sob controle do Estado, a propaganda estatal, a reescrita da história, os

\footnotetext{
5 Mbembe afirma que nem sempre esse poder é o estatal, mas é essa a acepção que adotaremos, considerando nossos objetos de pesquisa.

${ }^{6}$ No original: "And concretely, this translates, in the political effectivity of the thing, not only as an all-power of the state over life-death, the right of pardon, generation, birth, sexual potency as generative and demographic power, but also the height from which the state has the power to see everything, to see the whole, having literally, potentially, a right of inspection over everything".
} 
discursos de afirmação e de identidade. Resgatemos as bandeiras espalhadas pelo país após o 11 de Setembro. São símbolos nacionais em torno dos quais se imagina uma nação, a certeza do pertencimento, o apagamento da individualidade para integrar um "nós" supostamente horizontal. Matar ou morrer pela nação - todos parecem dispostos a esse extremo, mas nem todos o vivenciam (ANDERSON, 2008).

Deparamo-nos, assim, com outra dupla: patriotismo e nacionalismo. A princípio parece ser a diferença entre escolha e obrigação; você nasce dentro de determinado espaço, entre linhas imaginárias que demarcam um território, e, até o fim de sua vida, é àquele território que deve lealdade. 0 nacionalismo exige isso, qualquer conduta diferente é considerada traição. 0 patriotismo acredita na reformabilidade dos cidadãos e espera que você opte por isso, mesmo sem ter nascido naquele pedaço de terra.

Há os corpos que, uma vez situados dentro de certas fronteiras, estão sujeitos à violência, ao ódio de doutrinas e de ideologias, baseado no desconhecimento. Há os corpos que, quando menos esperam, se veem militarizados, enviados para uma terra distante da sua para eliminar a vida de outros corpos com os quais nunca nem mesmo se cruzaram. E todos esses corpos podem ser encontrados tanto "aqui" quanto "lá", mostrando mais uma vez que as figuras da vítima e do algoz frequentemente se confundem.

Esse estado de exceção - no qual a lei, a democracia e a justiça são dessignificados - justifica-se pela necessidade de levar a lei, a democracia e a justiça ao Outro que não é civilizado, cuja vida não consiste em nada além de um obstáculo para a instauração da ordem e de um projeto de poder global. Uma vida que, somada a outra vida, e a outra, e a outra, representa uma barreira anônima a ser derrubada.

Que efeitos teve a matança de aproximadamente 200 mil cidadãos iraquianos, incluindo milhares de crianças, sobre a visão muçulmana dos Estados Unidos? [...] Uma vida muçulmana é tão valiosa e decifrável como uma vida do Primeiro Mundo? A política e a imprensa norte-americanas já premiaram os palestinos com o status de "humanos"? Essas centenas de milhares de vidas muçulmanas perdidas durante as últimas décadas de conflitos receberam alguma vez o equivalente dos obituários de um parágrafo do New York Times que buscam humanizar norte-americanos assassinados violentamente - muitas vezes por meio de uma operação de enquadramento nacionalista e familiar? Nossa capacidade para um dano de dimensão global está foracluída precisamente pelo fracasso em conceber as vidas muçulmanas e árabes como vidas? (BUTLER, 2006, p. 36 , grifos da autora, tradução nossa). ${ }^{7}$

Embora toda guerra tenha um fim, para quem sobrevive ela é interminável: para os soldados do território ocupado, que precisam lidar com os rastros da violência que exerceram e à qual foram submetidos; para os soldados que retornam ao país de origem,

\footnotetext{
7 No original: “¿Qué efectos tuvo la matanza de aproximadamente 200.000 ciudadanos iraquíes, incluidos miles de niños, sobre la visión musulmana de los Estados Unidos? [...] ¿Una vida musulmana es tan valiosa y descifrable como una vida del Primer Mundo? ¿La política y la prensa norteamericanas ya le han adjudicado a los palestinos el estatus de 'humanos'? Esas cientos de miles de vidas musulmanas perdidas durante las últimas décadas de conflictos, ¿recibirán alguna vez el equivalente de los obituarios de un párrafo del New York Times que buscan humanizar a norteamericanos asesinados violentamente - a menudo por medio de una operación de encuadre nacionalista y familiar? ¿Nuestra capacidad para un duelo de dimensión global está forcluida precisamente por el fracaso de concebir las vidas musulmanas y árabes como vidas?".
} 
traumatizados, sofrendo as ressonâncias do que viram e fizeram capazes de atos que nunca saberemos se vieram de seu próprio caráter, dos horrores da guerra ou de algum código nacionalista incluído nas programações do híbrido humano-arma que se tornaram; para as famílias e para o que restou das populações, deixados para cuidar dos corpos e dos destroços; para as mulheres, a sós com a sombra de agressões físicas, estupros, gravidezes e crianças indesejadas nascidas da violência sexual, com os fantasmas daqueles que perderam e das perspectivas de futuro que não conseguem enxergar; e para os senhores da guerra, que já buscam em seus horizontes uma nova guerra para empreender.

\section{Inimigo objetivo externo: quando o Outro não está nas minhas fronteiras}

A figura do inimigo externo aparece e reaparece na cultura mainstream estadunidense, seja na figura do russo (evocando a Guerra Fria), seja na do fundamentalista islâmico (mais recente, relacionada ao 11 de Setembro). Apesar de o inimigo objetivo ser sempre o Outro, como já mencionamos, nesse caso ele se apoia em preconceitos contra o estrangeiro e usa conflitos anteriores como justificativa para direcionar a essas populações o medo e o ódio. Além disso, no caso específico dos Estados Unidos, ancora-se também no Americanismo, ou seja, na noção de que o estadunidense faz parte de um povo escolhido, merecedor de bênçãos divinas, e de que todo aquele que for contrário a esse preceito é, portanto, inimigo da nação (PECEQUILLO, 2003, p. 65).

Desde o 11 de Setembro de 2001, todos os problemas e as violências que os Estados Unidos sofreram se personificaram na figura do terrorista islâmico. Para consolidar nesse novo estrangeiro o inimigo objetivo, inúmeras produções midiáticas espetacularizaram e romantizaram o conflito.

Para nossa análise, escolhemos o quadrinho Holy Terror, de Frank Miller, para contrapor à leitura de Jogos Vorazes. Diferentemente da trilogia juvenil, o quadrinho mostra um protagonista adulto em uma cidade fictícia, mas com semelhanças visíveis à cidade de Nova Iorque. Enquanto na obra de Suzanne Collins a distopia já está estabelecida, na HQ de Miller vemos o que pode se configurar como o início de um futuro distópico.

O quadrinho se inicia apresentando um panorama do espaço onde se passa a narrativa, do macro para o micro. Mostra primeiro uma estátua que orna a cidade, então passa a focar os dois protagonistas em uma relação de perseguição/fuga. A Gatuna - alterego de Natalie Stack é uma ladra de joias que salta pelos telhados da cidade, fugindo do homem que atua como vigilante mascarado na metrópole, após ter roubado "uma simples pulseirinha" (MILLER, 2013, p. 11). O (antiJherói, Censor, alcança a Gatuna, e ambos começam um combate corpo a corpo marcado principalmente pela tensão sexual entre os personagens.

Durante o conflito, os protagonistas são surpreendidos por uma explosão, que lança pregos em todas as direções e forma uma fumaça que faz o vigilante vomitar. Um dos pregos atinge a ladra na perna, fazendo-a reclamar de dor. "Jesus Cristo! Jesus, isso dói pacas" (MILLER, 2013, p. 31). o Censor então, tentando consolá-la e não sabendo como se portar nessa situação, se dirige a Stack, dizendo: "Eu sei que dói, gata, eu 
sei que dói” (Id., p. 33). Esse foi o primeiro de uma série de ataques mostrados no quadrinho.

Notamos aqui uma performance de brutalidade. 0 homem, musculoso, violento e viril, não sabe demonstrar sentimentos, não consegue consolar apropriadamente e nem se permite manifestar afeto. Essa última parte é evidenciada adiante na narrativa quando o Censor mostra seus dilemas pessoais através do recordatório, afirmando que "não quer e não deve se apaixonar" (MILLER, 2013, p. 66), referindo-se à Gatuna.

Enquanto ambos protegem-se dos estilhaços das explosões, é descrita a forma como os protagonistas se comportam em meio aos ataques. Ela está “zonza e fraca, em pânico” (MILLER, 2013, p. 40), enquanto o vigilante "também treme, mas de raiva. Como se ele quisesse começar a matar gente" (Idem). Ao contemplarem a cidade destruída, os agora heróis se reerguem afirmando: "Não. Não no meu turno. Não no meu pedaço. Não na minha cidade" (MILLER, 2013, p. 56). Como o próprio Censor já havia dito à Gatuna, "Isso era guerra" (Id., p. 32), conforme imagem abaixo.

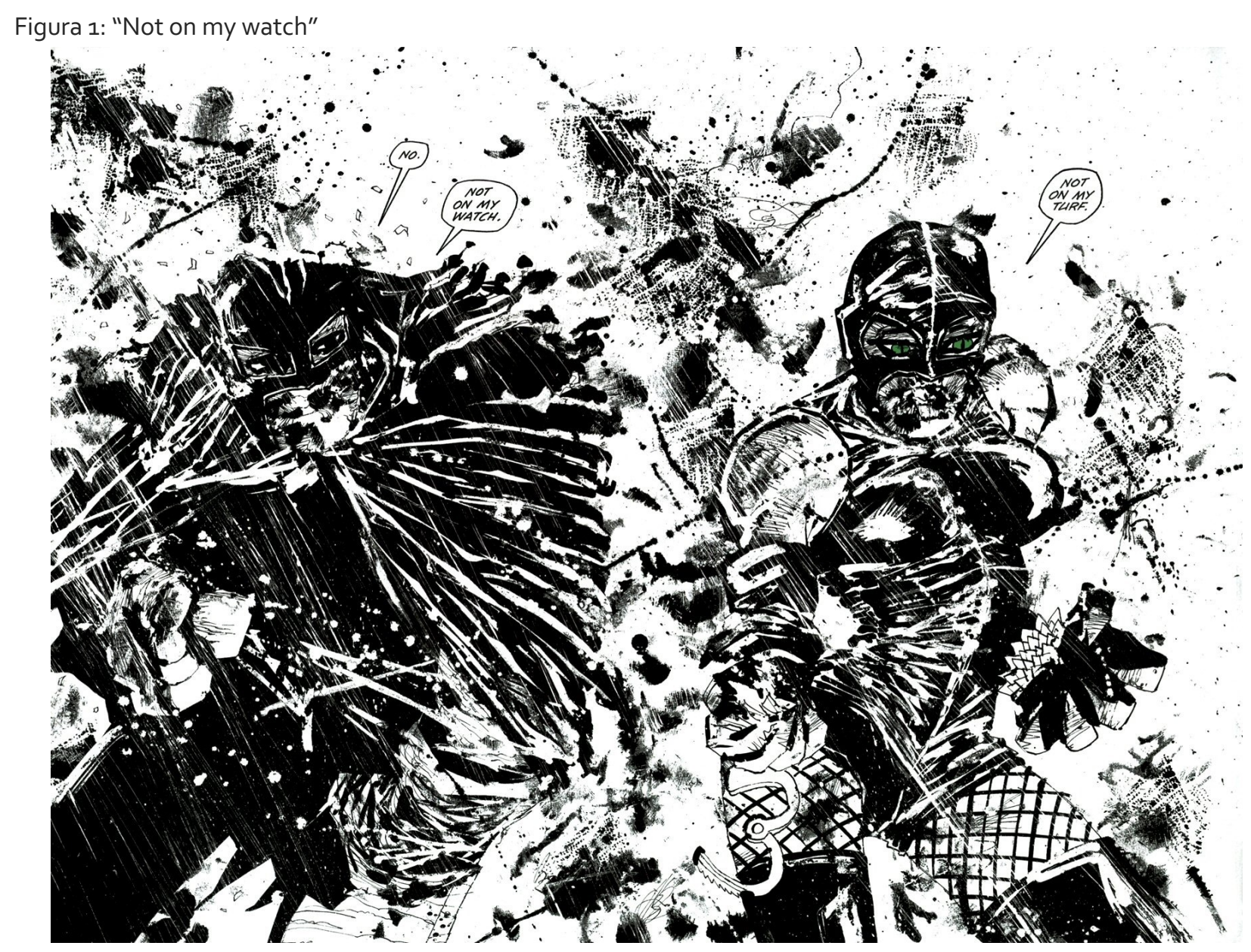

Fonte: MILLER (2013, p. 56).

A razão se apaga e a violência é combatida com força bruta. $\mathrm{O}(\mathrm{s})$ responsável(is) merece(m) ser responsabilizado(s). Aqui retomamos o que foi dito na seção anterior: uma vez situados dentro de certas fronteiras, há corpos sujeitos à violência, ao ódio de doutrinas e de ideologias. Vemos no Censor um nacionalismo exacerbado. É esperado 
dele, na condição de vigilante, que proteja seu território a todo custo. E ele influencia Gatuna, que, antes ladra, se torna (anti-)heroína.

Contudo, temos também corpos que, inesperadamente, se veem militarizados, enviados para uma terra distante da sua para eliminar a vida de outros corpos com os quais nunca nem mesmo se cruzaram. Para exemplificarmos, retrocedemos então para dez minutos antes da explosão. Nesse momento, é introduzida a personagem intercambista chamada Amina. Jovem, com maquiagem bem marcada ao redor dos olhos, ela descreve a cidade onde se passa a história: "Esnobe.

Arrogante. Sempre se fazendo maior, mais alta como um bando louco e ruidoso de robôs. Sempre subindo. [...] Empire City. América" (MILLER, 2013, p. 35). Amina segue na sua reflexão sobre a cidade, já adotando um tom mais profético: "Alarmes de carro berram como pirralhos mimados. Sirenes vêm na sequência. Empire City vai gritar. Em agonia” (MILLER, 2013, p. 36).

A garota está em um telhado de uma casa noturna e interage com um rapaz mais ou menos da idade dela. Eles trocam algumas palavras, e ela pede um gole da cerveja dele, dizendo ser seu "primeiro trago na vida [já que] de onde eu venho não se bebe álcool" (Id., p. 37). Ainda destacamos a naturalidade com a qual a personagem destaca que "coisas explodem o tempo todo", conforme a imagem abaixo.

Figura 2: Amina em sua primeira aparição em Holy Terror

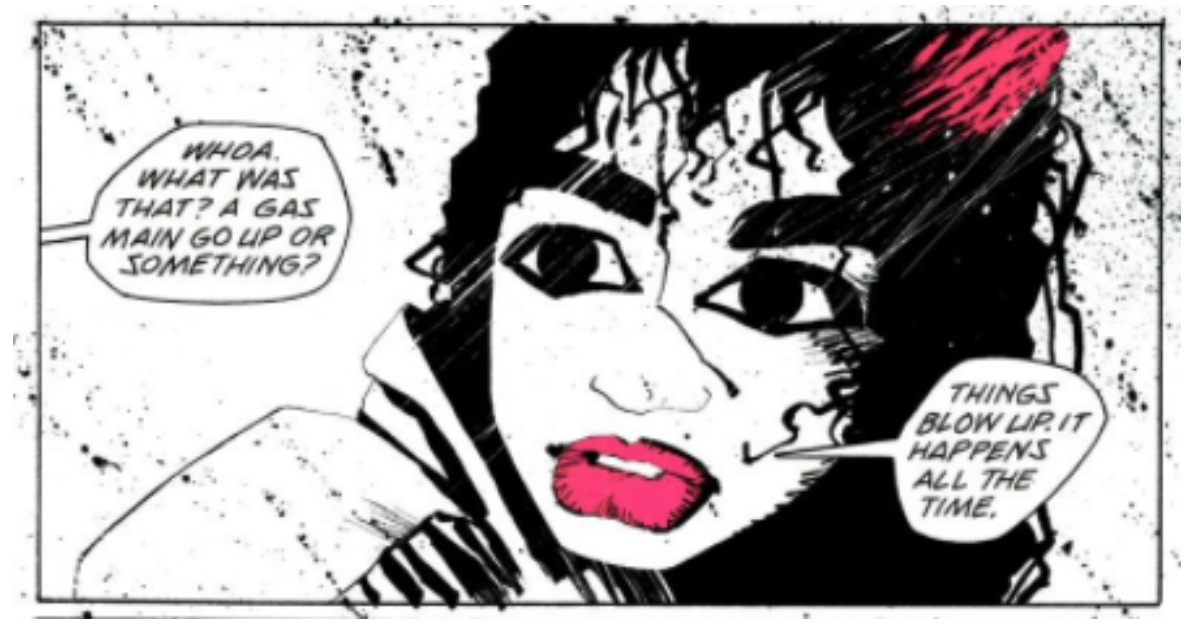

Fonte: MILLER (2013, p. 37).

Ela e o garoto descem juntos para a festa. $\mathrm{O}$ ambiente está lotado, e ela pede para ficar bem perto dele. Ele sente um volume sob o casaco da menina e pergunta do que se trata, e ela responde: "o paraíso" (Id, p. 38). 0 quadrinho corta para uma página cheia, que enfatiza os pregos voando pelo ar, então mostra que estão acontecendo ataques consecutivos à cidade. A narrativa dá a entender que Amina era uma garota-bomba, responsável por pelo menos uma das explosões que assolam Empire City. Infere-se também que a intercambista venha de algum país do Oriente Médio, pela postura e pelos costumes.

É interessante perceber que há uma relação de complementaridade. Os Estados Unidos, representados pelo Censor e pela Gatuna, projetam o seu inimigo em uma organização terrorista, responsável pelos ataques dentro do país. São, portanto, corpos externos, que não compartilham do seu idioma, das suas crenças ou do 
seu patriotismo. Por outro lado, Amina, bem como outros possíveis adolescentes que se explodiram para atacar os EUA, também possuem crenças e costumes comuns a seu país de origem. 0 inimigo é sempre o Outro, aquele que interfere no meu território e não faz parte do meu coletivo.

Outrora inimigos, o Censor e a Gatuna aliam-se para solucionar os casos de terrorismo que atingem Empire City. 0 vigilante revela que possui um contato dentro do departamento de polícia, o Capitão Dan Donegal. 0 policial havia sido introduzido poucas páginas antes, correndo e mobilizando toda a força policial para intervir nas explosões. Apontamos aqui que, por causa do terrorismo ocorrido na cidade, houve uma união entre polícia, vigilante e bandido. Como se as diferenças entre eles sumissem por um instante contra um inimigo comum.

O Censor e a Gatuna conseguem informações sobre os próximos movimentos da célula terrorista responsável pelos ataques. Conclui-se que a organização é a Al-Qaeda. Os protagonistas conseguem informações sobre o local onde os terroristas estão instalados ao conversar com o já citado capitão da polícia, com um outro vigilante que atua sob a alcunha de Davi (com uma Estrela de Davi tatuada no rosto), e também torturando um dos terroristas.

Depois de novas explosões na cidade, os protagonistas ensaiam então um ataque ao quartel-general da Al-Qaeda, começando com uma missão de infiltração. Após a apresentação do plano dos terroristas, Gatuna e Censor vestem uma máscara de oxigênio, e este último detona a bomba (que seria usada pela Al-Qaeda) dentro do QG da organização, matando a todos. A um último terrorista (talvez o líder) é reservada uma morte lenta e dolorosa, despedaçando seu corpo no gás tóxico da explosão. 0 Censor é carregado, bastante ferido e beirando a inconsciência, para a superfície; de acordo com Stack: "o ar está limpo, graças a você" (MILLER, 2013, p. 110).

Na última cena do quadrinho, é mostrado o policial, que se aliou ao Censor, acordando em seu quarto, tremendo e traumatizado:

Figura 3: Dan Donegal relembrando as cenas de violência das semanas anteriores

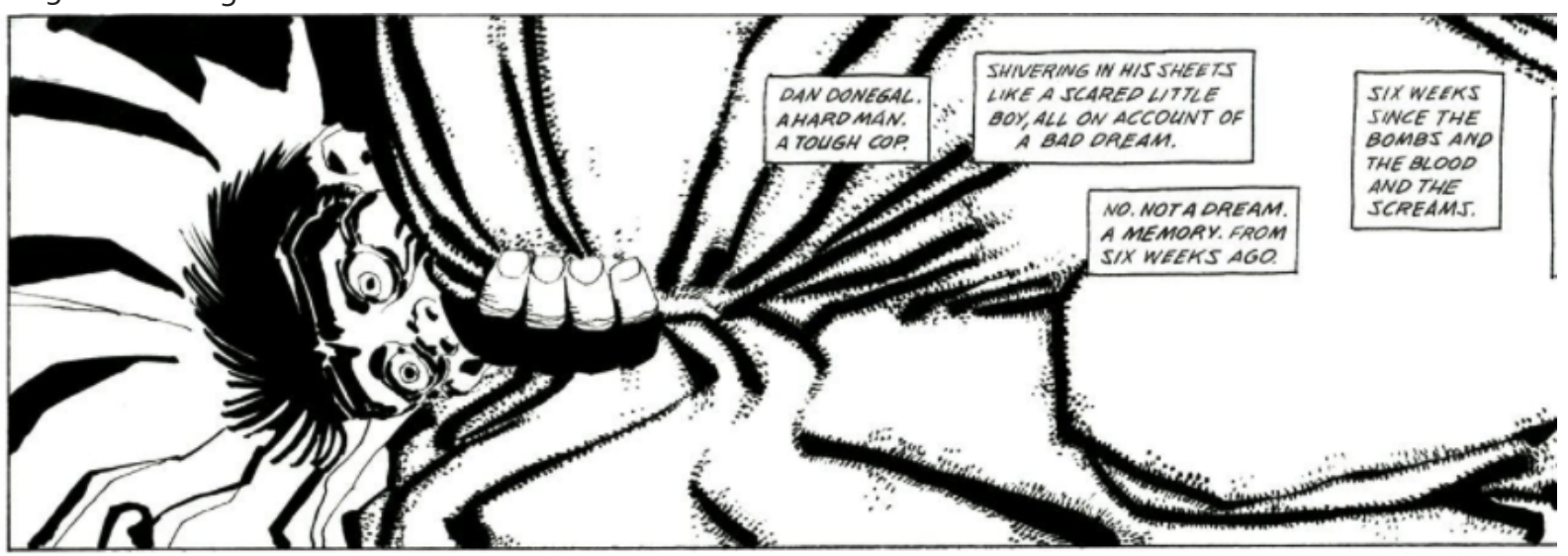

Fonte: MILLER (2013, p. 112).

Não só o Censor carrega no corpo as marcas físicas da violência, como também o policial, antes descrito como "policial casca-grossa, homem durão" (MILLER, 2013, p. 57), carrega marcas psicológicas. Treme sozinho na cama ao relembrar os eventos que ocorreram em 
Empire City seis semanas antes. Nota-se que ao ser reintroduzido, é marcado novamente que ele seja "durão, casca-grossa" mas é acrescentado que treme encolhido nas cobertas. Os olhos arregalados denotam insônia ou noites mal-dormidas - creditadas a pesadelos que são, na verdade, memórias reais, do que foi vivido. Diferentemente do Censor, que teve marcas físicas explicitadas, como cortes, hematomas e sangue excretado do corpo, as marcas de Donegal são vistas seis semanas depois. São marcas que perduram.

\section{Inimigo objetivo interno: comunidade e pensamento abissal}

Feitas as considerações sobre o inimigo objetivo externo no âmbito da cultura mainstream estadunidense, passemos agora para a figura do inimigo objetivo interno. Para isso, como mencionamos, faremos uma análise desse aspecto na trilogia Jogos Vorazes. ${ }^{8}$ Antes de iniciar tal análise, porém, apresentaremos rapidamente um resumo da obra.

A narrativa se passa em uma nação chamada Panem, fundada após uma série de conflitos e catástrofes terem destruído a América do Norte. ${ }^{9}$ Panem foi inicialmente dividida em 13 distritos - cujos habitantes trabalhavam em condições de miséria e exploração para sustentar os luxos de quem vivia na Capital. Posicionando-se contra essa situação de exploração, o Distrito 13, responsável pela defesa militar de Panem, liderou os outros em uma revolta contra o governo autoritário da Capital - um episódio que ficaria marcado na história do país como os "Dias Escuros" -, mas logo o levante foi sufocado, e o Distrito 13, supostamente reduzido a cinzas.

Como punição aos outros distritos pelos Dias Escuros, a Capital organizou uma competição chamada Jogos Vorazes - um evento anual, obrigatoriamente televisionado para toda Panem, em formato de reality show. Uma equipe da Capital vai a cada distrito e realiza uma cerimônia chamada de "colheita", que consiste basicamente em sortear uma garota e um garoto de 12 a 18 anos, os tributos. Após um curto período de treinamento e de aparições em rede nacional de televisão, os 24 tributos são confinados em uma arena e devem se digladiar até restar apenas um sobrevivente. Como incentivo, são oferecidos ao ganhador a possibilidade de ascensão social, uma vida livre de trabalho forçado, uma casa na Aldeia dos Vitoriosos, além de um ano de comida para todas as pessoas de seu distrito - tudo a que não teria acesso de nenhuma outra forma em Panem.

0 primeiro livro se inicia na colheita da 74a edição dos Jogos Vorazes. A protagonista é Katniss Everdeen, uma adolescente de 16 anos do Distrito 12, que se torna tributo ao se voluntariar para tomar o lugar da irmã, Primrose Everdeen, de 12 anos, que havia sido sorteada para participar da competição.

Nesse contexto, em que o Estado-nação se divide de acordo com as categorias de Buck-Morss (2018) - ou seja: de um lado, um mundo de

\footnotetext{
8 É necessário esclarecer que, neste artigo, serão analisados apenas os livros. Embora possam ser mencionadas em determinados momentos do texto, a título de complemento, as adaptações cinematográficas não figuram como objeto desta análise.

${ }^{9}$ Não fica explícito se a autora se refere à América do Norte inteira (incluindo Canadá e México) ou apenas aos Estados Unidos. Considerando, porém, as pistas que ela dá a respeito da geografia de Panem ao longo da trilogia, bem como o fato de que os Estados Unidos se autodenominam "América", adoto, para efeitos de análise, a última opção.
} 
sonho; do outro, um mundo de catástrofe -, o inimigo objetivo interno pode se apresentar de diversas maneiras. Optamos, aqui, por nos aprofundarmos em duas delas. A primeira seria a formação de comunidade, que se dá pela escolha do adolescente como figura inimiga. Quanto à segunda, trata-se do conceito de pensamento abissal (SANTOS, 2007).

\subsection{Inimigo objetivo e formação de comunidade: o adolescente como ameaça}

Como mencionamos, o conceito de inimigo objetivo interno está implicado no processo de formação de comunidade - aliás, na criação de um sentido de comunidade. Em Panem, a oposição entre gerações gera uma estrutura social que se mantém por meio do assassinato de crianças e de adolescentes. Perda de inocência e de infância são fundamentais para perpetuar o domínio da Capital, e isso se dá com a silenciosa aquiescência dos adultos dos distritos. Figuras intermediárias entre o desamparo das crianças e a omissão dos adultos, os adolescentes se tornam as únicas alternativas viáveis para desafiar esse domínio, empreender ações revolucionárias e repensar as formas de cidadania.

Ao mesmo tempo, são esses revolucionários solitários que se tornam os bodes expiatórios. Em vista da probabilidade de causarem transtornos, são utilizados para restaurar o equilíbrio. Empregam-se modos autorizados de violência para reprimir a violência não autorizada. 0 adolescente é visto não apenas como um repositório de punição para crimes que foram cometidos antes mesmo de sua existência, mas para crimes que possivelmente venha a cometer.

É preciso reorientar esse potencial rebelde carregado de violência, utilizá-lo para servir aos interesses do Estado-nação. Ritualizada, a brutalidade ressurge sob a forma de sacrifício e restaura uma harmonia ilusória que nunca existiu de fato, apenas se imaginou. 0 tecido que forma a rede da comunidade se preserva por mais algum tempo. A vítima, aqui o adolescente, é suficientemente parte da comunidade para servir como objeto desse sacrifício, mas apenas suficientemente. $\mathrm{Na}$ verdade, ele é o limite entre o que é interior e o que é exterior, entre o familiar e o estranho. Uma das poucas características que compartilha com sua comunidade é a responsabilidade arbitrária pelos crimes passados, presentes e futuros.

Assim, os adolescentes se tornam Outros, estrangeiros em seu próprio distrito. Uma ameaça a ser eliminada pelo bem de todos, um inimigo objetivo inventado. Mesmo quando vencem os Jogos, os tributos permanecem como sujeitos apartados de suas comunidades; o modo como são segregados espacialmente na Aldeia dos Vitoriosos é uma evidência dessa estrangeiridade.

0 papel dos adultos nessa dinâmica implica inércia, mudez, desempoderamento. Por terem de conviver com seus próprios traumas, não conseguem se recompor o suficiente para uma ação política efetiva em defesa das crianças e dos adolescentes condenados à morte. Há uma infantilização da figura adulta, transformando-a em um corpo que precisa de cuidados, como a mãe de Madge e suas dores de cabeça; ou uma figura que é incapaz de lidar com a paralisia causada pelo choque, como a mãe de Katniss; ou que é incapaz de controlar até mesmo suas funções corporais, como Haymitch e seu vômito por causa da bebida.

Memorare, Tubarão, v. 8, n. 1, jan./jun. 2021. ISSN: 2358-0593 
A passividade dos adultos - seja como espectadores das mortes, seja como vítimas eles próprios - é condição necessária para o estabelecimento de qualquer regime autoritário. Arendt (2013) descreve o modo como as populações judaicas se submeteram ao genocídio perpetrado pelos nazistas, “[...] chegando pontualmente nos pontos de transporte, andando sobre os próprios pés para os locais de execução, cavando os próprios túmulos, despindo-se e empilhando caprichosamente as próprias roupas, e deitando-se lado a lado para ser fuzilados [...]", justamente porque a estrutura montada pelo governo aniquilava as vítimas antes mesmo de matá-las. "Há muitas coisas consideravelmente piores do que a morte, e a SS [Schutzstaffel, organização militar nazista] cuidava que nenhuma delas jamais ficasse muito distante da mente e da imaginação de suas vítimas" (ARENDT, 2013, p. 22-23).

Por medo dessa morte em vida, os judeus aceitavam tomar para si a responsabilidade abominável que lhes era forçada: cuidar de todos os detalhes da morte dos seus - o trabalho nas câmaras de gás e nos fornos onde eram cremados os prisioneiros, a limpeza dos corpos, a abertura das covas. Sem contar os judeus que se tornavam carrascos, bem como a cumplicidade das elites judaicas, que criavam governos de fachada para encobrir os massacres nazistas. Da mesma forma funciona a dinâmica social em Panem, uma situação que amplia o abismo entre membros do mesmo grupo e desvia a atenção deles da verdadeira ameaça, do verdadeiro inimigo - o que leva ao conceito de pensamento abissal.

\subsection{O "Eu" e o "Outro": considerações sobre o pensamento abissal}

Sabemos, para iniciar tais considerações sobre o conceito de pensamento abissal, que a negação faz parte da identidade. Ser o "Eu" significa não ser o "Outro", afastar de si qualquer possibilidade de identificação com aquele que é considerado oposto (SILVA, T., 2000) - o que está estritamente relacionado ao conflito entre adultos e adolescentes e, por consequência, ao conceito de inimigo objetivo. Ser o Eu é ter poder de marcar o Outro como diferente enquanto o próprio Eu continua não marcado. A dor do Outro é alheia, não porque o Eu não a vê, mas porque lhe interessa apenas o que ela causa.

O Outro é aquele que nada tem a oferecer ao Eu - ou à Capital, ou ao capital - além do trabalho que supre as necessidades e do entretenimento que tira a vida do tédio absoluto. 0 corpo e a imagem do Outro servem apenas para o prazer do Eu. Esse Eu vê as diferenças e as utiliza a seu favor, transformando o Outro no inimigo objetivo para se distanciar dessa figura terrível, para reafirmar sua individualidade. E essa individualidade não se dá no sentido de subjetividade, mas sim no sentido do isolamento em si mesmo.

O Outro revela e expõe o Eu - não aos perigos que vêm de buracos e esquinas onde, imagina-se, esse Outro se esconde; mas revela e expõe o Eu ao pior de si, aos seus preconceitos e aos seus ódios, sejam eles particulares, sejam coletivos. Semelhantemente ao estrangeiro de Kristeva, o Outro (tanto o inimigo objetivo interno quanto o externo) tem "[...] a capacidade de expor claramente o que as relações humanas têm de mais abrupto, quando eclipsa-se a sedução, e as conveniências cedem em proveito do julgamento dos confrontos: choque dos corpos e

Memorare, Tubarão, v. 8, n. 1, jan./jun. 2021. ISSN: 2358-0593 
dos humores" (KRISTEVA, 1994, p. 15), mostrando que estamos acostumados ao inacostumável.

Para evitar esse encontro, traça-se então uma linha que pode ser tanto visível quanto invisível. Uma fronteira, um muro ou uma grade. Um discurso, um estereótipo ou uma crença. Isto é, existem os que estão do lado de cá e os que estão do lado de lá. Essa é a base do pensamento abissal, conceito criado por Santos (2007).

Tudo o que está do outro lado da linha adquire um caráter de invisibilidade, inexistência, irrelevância e incompreensão. Deste lado da linha, segundo Santos (2007), lidamos com a tensão entre regulação e emancipação, ou seja: a regulação efetuada pelo Estado, pelo mercado e pela comunidade, que se contrapõe à emancipação da estética, da ciência, da tecnologia, da ética e do direito. Do outro lado, qualquer tipo de emancipação seria impensável, assim como a regulação, que abre espaços para negociações. Quem se encontra do lado de lá se defronta com o par apropriação/violência. Em geral, "[...] a apropriação envolve incorporação, cooptação e assimilação, enquanto a violência implica destruição física, material, cultural e humana" (SANTOS, 2007, p. 75).

"O Distrito 12 é bem o fim da linha. Mais além, só existe vastidão selvagem" (JV, p. 92, grifos nossos). Para Katniss e os distritos, a linha se localiza no espaço onde começam as ruínas do Distrito 13; para a Capital, o outro lado compreende tudo e todos além de sua fronteira. Do lado de lá, há o Outro incapaz de abandonar o estado de natureza, o espaço de vastidão selvagem, para formar de fato uma sociedade civil(izada).

- Mas tenho andado um pouco nas nuvens - diz ela [Effie Trinket], seus olhos quase fechados. - Porque, é claro, Haymitch nem se preocupou em me dizer quais eram as estratégias de vocês. Mas dei o melhor de mim naquilo em que eu mais devia trabalhar: como Katniss sacrificou a si mesma pela irmã. Como vocês dois lutaram com sucesso para superar a barbárie do distrito em que vivem.

Barbárie? Isso chega a ser irônico vindo de uma mulher que está nos ajudando a nos preparar para uma chacina. E em que ela está baseando nosso sucesso? Em nossas maneiras à mesa? (JV, p. 83).

São doze (ou treze) os distritos submetidos à lógica da apropriação/violência, enquanto há apenas uma Capital que equilibra regulação/emancipação sobre seus habitantes, com amplas aberturas para ajustes. Qualquer ato impensável praticado contra aqueles do lado de lá, seja o inimigo objetivo interno, seja o externo, se justifica pela proteção dos princípios civilizados deste lado: “[...] direitos humanos são violados para que possam ser defendidos, a democracia é destruída para que se garanta sua salvaguarda e a vida é eliminada em nome da sua preservação" (SANTOS, 2007, p. 79).

Formam-se as condições para o que Santos (2007) chama de fascismo social, um sistema que envolve relações desiguais de poder, em que o lado mais forte da linha possui "poder de veto sobre a vida e o modo de vida da parte mais fraca" (SANTOS, 2007, p. 80). Direitos sociais, econômicos, trabalhistas e legais são negados a determinadas parcelas das populações. Assistimos ao fortalecimento de uma matriz opressora que assume múltiplas configurações, sempre baseada na 
desigualdade e em constante mudança de acordo com os interesses de grupos dominantes deste lado da linha.

Considera-se generosidade permitir que aqueles do lado de lá experimentem um pouco daquilo que é nosso por direito - a fartura de comida, os chuveiros com cheiro de rosas ou a glória da beleza artificial exibida em desfiles de carruagens -, mesmo que por apenas alguns dias antes de serem lançados em um jogo voraz de morte. Os medos do lado de cá tornam o lado de lá um todo homogêneo baseado em uma palavra: "potencial". Potencial inimigo, potencial perigo, potencial criminoso. E a punição se aplica a todos:

O mundo dos agonizantes, no qual os homens aprendem que são supérfluos através de um modo de vida em que o castigo nada tem a ver com o crime, em que a exploração é praticada sem lucro, e em que o trabalho é realizado sem proveito, é um lugar onde a insensatez é diariamente renovada. [...] Se os presos são insetos daninhos, é lógico que sejam exterminados por meio de gás venenoso; se são degenerados, não se deve permitir que contaminem a população [...] (ARENDT, 2013, p. 387).

Mais importante do que a punição em si, entretanto, é o que ela representa: uma forma de controle social, de utilizar aqueles corpos matáveis para manter as divisões exatamente onde elas estão, porque é assim que o sistema continua em equilíbrio. Qualquer alteração na estrutura punitiva, qualquer apagamento na figura do inimigo objetivo, leva ao seu colapso.

- Ocorreram levantes? - pergunto, não só tremendo de medo, mas também um pouco exultante diante da possibilidade.

- Ainda não. Mas ocorrerão se o curso dos acontecimentos não mudar. E é sabido que levantes levam a revoluções. [...] Você faz alguma ideia do que isso significaria? De quantas pessoas morreriam? Das condições que os sobreviventes teriam de enfrentar? Independentemente dos problemas que alguém possa ter com a Capital, acredite quando digo que se ela lançar suas garras sobre os distritos, mesmo que por um curto período de tempo, todo o sistema desmoronará.

[...] Como se a sua principal preocupação fosse o bem-estar dos cidadãos de Panem, quando na verdade nada poderia ser mais distante da verdade do que isso. Não sei como ouso dizer as palavras seguintes, mas digo. - Ele deve ser muito frágil mesmo, se um punhado de amoras pode derrubá-lo (EC, p. 28-29).

A morte desse Outro do outro lado da linha serve para encobrir essa vulnerabilidade, da mesma forma que a morte do inimigo inventado encobre a vulnerabilidade dos Estados Unidos. 0 mesmo ocorre com os suplícios de que fala Foucault (2013), ou seja, os métodos de tortura e de punição de infratores da lei, que estiveram em voga até o século 19. Mais do que um castigo para o crime que cometeram, mais do que um exemplo a ser dado, promovia-se uma política do medo. Tudo que se refere aos Jogos serve a esse propósito, ao mesmo propósito dos suplícios: "Os seus excessos, o seu espetáculo, a violência corporal, um jogo desmesurado de forças, um cerimonial meticuloso, em suma, todo o seu aparelho se inscrevia no funcionamento político da penalidade" (FOUCAULT, 2013, p. 40). Dessa maneira, os discursos dominantes se propagam, a política do medo entra em ação e as insurgências tendem a não se repetir. 


\section{Considerações finais}

Nesse contexto, as vidas do lado de cá da linha são preservadas a todo custo; são as vidas humanas, sagradas em sua permanência. As vidas do lado de lá, em sua instrumentalidade, são preservadas o suficiente para se manterem produtivas, até atingirem o ponto de esgotamento que as torna descartáveis. Ou então sua instrumentalidade reside justamente em sua matabilidade, como o inimigo objetivo inventado.

Por essa incoerência entre preservação da vida e produção de morte, assistimos a aberrações como os pacotes de alimentos e remédios lançados pelo governo estadunidense aos cidadãos afegãos na Guerra do Afeganistão, no mesmo espaço e no mesmo contexto bélico que as bombas destinadas a dizimá-los. Como a armadilha montada pelos rebeldes para minar o que restava do poder do presidente Snow sobre Panem: uma barricada de crianças da Capital, bombardeadas pelos paraquedas prateados que viram desde sempre na televisão, um objeto ao qual associavam a palavra "dádiva" e que levava aos tributos os itens de que precisavam para sobreviver na arena. Ou, ainda, na garota-bomba Amina, que personificou na HQ de Miller uma das múltiplas explosões que ocorreram em Empire City. Uma adolescente intercambista que passou os últimos momentos em uma festa, bebendo com outros jovens da mesma faixa etária - isto é, aproveitando uma vida ocidentalizada à qual até então não tivera acesso -, até o momento em que se tornou descartável.

Quanto maior a tensão causada pelo terror, maior a segurança mas apenas para um dos lados da linha; quanto mais violados os inimigos objetivos do lado de lá, mais invioláveis estamos do lado de cá, mesmo que o medo faça parte da experiência. Ou seja, "[...] a vida se defende e se desenvolve apenas mediante um alargamento progressivo do círculo da morte" (ESPOSITO, 2017, p. 139).

É necessário decidir com cautela quais vidas constam na lista daquelas que podem ser cessadas. São as que Athena Athanasiou e Judith Butler (2013) chamam de "disposable", ou descartáveis; vidas e corpos sempre limitados por pessoas, instituições, normas e normatividades, sujeitos a uma precariedade condicionada. Bauman (2005) dá outro nome para a mesma categoria: vidas redundantes, oriundas da produção de refugo humano, que gera consequentemente os locais de despejo e de reciclagem do lixo - locais que, podemos adivinhar, ficam bem do outro lado da linha.

Vidas descartáveis/redundantes são aquelas expostas a dinâmicas e violências que as tornam vulneráveis - desapropriação de terras, exílio, diáspora e imigração, perda do controle e da posse do próprio corpo, miséria, fome, desemprego, doença, tortura, apartheid, regulação da sexualidade, regulação de aspectos relacionados ao gênero, agressão sexual, exploração do trabalho e seus efeitos no corpo do trabalhador, analfabetismo, precarização da educação e da saúde, transformação da vida em capital, abandono.

Em Panem, as vidas descartáveis estão na população dos distritos, em especial as crianças e os adolescentes. São também as crianças na própria Capital, como Coin provou quando sugeriu fazer uma edição 
simbólica dos Jogos Vorazes para aplacar a fúria daqueles que queriam vingança. São os avoxes, forçados ao silêncio e à servidão para pagar uma dívida que nunca fizeram. Em Empire City, são quadros de rostos genéricos que se multiplicam e evanescem, representando as vítimas residentes da cidade. São os próprios terroristas, adolescentes ou adultos, que dão suas vidas em solo estrangeiro para ferir outro, em nome da sua fé ou patriotismo. Em ambos os casos, são exemplos de bodes expiatórios.

Submeter esse Outro à violência, principalmente no caso da violência de Estado, é uma estratégia soberana para deslocar a vulnerabilidade. 0 sentimento de estar vulnerável é indigesto; a soberania é frágil e extremamente permeável quando se trata desse tipo de exposição. A resposta violenta consiste em uma maneira de transferir a vulnerabilidade para outras pessoas, outros espaços, outras nações para o inimigo objetivo.

Ou seja: a parte que se propõe soberana e dominadora faz o possível para limitar o Outro a condições que o acostumem à morte, que a naturalizem. A eliminação de fato, a morte física completa, “[...] se converte apenas no prolongamento de um jogo. Aparecem formas de crueldade mais íntimas, horríveis e lentas" (MBEMBE, 2011, p. 27, grifo nosso, tradução nossa). ${ }^{10} 0$ prolongamento de um jogo voraz que consiste em fazer com que a própria vida se pareça com a morte, suspensa em um estado de invisibilidade e de desamparo.

\section{Referências}

ALMINO, João. A utopia é um império: as relações entre os povos na obra clássica de Thomas More. In: MORE, Thomas. Utopia. Tradução de Anah de Melo Franco. Prefácio de João Almino. Brasília: Editora da UnB, 2004. p. IX-XXXIII.

AMES, Melissa. Engaging "apolitical" adolescents: analyzing the popularity and educational potential of dystopian literature post-9/11. Faculty Research \& Creative Activity: Eastern Illinois University, Illinois, n. 88, p. 3-20, out. 2013.

ANDERSON, Benedict. Comunidades imaginadas: reflexões sobre a origem e a difusão do nacionalismo. São Paulo: Companhia das Letras, 2008.

ARENDT, Hannah. Ideology and terror: a novel form of government. The Review of Politics, [S. l.], v. 15, n. 3, p. 303-327, 1953.

ARENDT, Hannah. Eichmann em Jerusalém: um relato sobre a banalidade do mal. São Paulo: Companhia das Letras, 1999.

ARENDT, Hannah. Origens do totalitarismo: antissemitismo, imperialismo, totalitarismo. São Paulo: Companhia das Letras, 2013. (Selo Companhia de Bolso).

BARBOSA, Anna Carolyna. 0 espaço, o humano e o espetáculo na distopia pósmoderna de Jogos Vorazes. 2017. Dissertação (Mestrado em Letras) Programa de Pós-Graduação em Letras, Universidade Federal de São João delRei, São João del-Rei, 2017.

10 No original: “[...] se convierte en la prolongación de un juego. Aparecen formas de crueldad mas íntimas, horribles y lentas”. 
BAUMAN, Zygmunt. Vidas desperdiçadas. Tradução de Carlos Alberto Medeiros. Rio de Janeiro: Zahar, 2005.

BENJAMIN, Walter. Iluminations: essays and reflections. Nova Iorque: Schoken Books, 2007.

BUCK-MORSS, Susan. Mundo de sonho e catástrofe: o desaparecimento da utopia de massas na União Soviética e nos Estados Unidos. Tradução de Ana Luiza Andrade, Ana Carolina Cernicchiaro e Rodrigo Lopes de Barros. Florianópolis: EdUFSC, 2018.

BUTLER, Judith. Vida precaria: el poder del duelo y la violencia. Buenos Aires: Paidós, 2006. 192 p.

BUTLER, Judith; ATHANASIOU, Athena. Dispossession: the performative in the political. Cambridge: Polity Books, 2013.

COLLINS, Suzanne. Jogos Vorazes. Tradução de Alexandre D'elia. Rio de Janeiro: Rocco, 2010.

COLLINS, Suzanne. Em Chamas. Tradução de Alexandre D'elia. Rio de Janeiro: Rocco, 2011.

COLLINS, Suzanne. A Esperança. Tradução de Alexandre D'elia. Rio de Janeiro: Rocco, 2012.

DERRIDA, Jacques. The beast and the sovereign. Chicago: University of Chicago Press, 2008.

ESPOSITO, Roberto. Bios: biopolítica e filosofia. Tradução de Wander Melo Miranda. Belo Horizonte: Editora da UFMG, 2017. 272 p. (Coleção Humanitas).

FOUCAULT, Michel. Vigiar e punir: o nascimento da prisão. Tradução de Pedro Elói Duarte. Lisboa: Edições 70, 2013.

GOODREADS. The dystopian timeline to The Hunger Games [INFOGRAPHIC]. [S. l.], 21 mar. 2012. Disponível em: https://www.goodreads.com/blog/show/351-thedystopian-timeline-to-the-hunger-games-infographic. Acesso em: 15 jul. 2020.

GURR, Barbara. Introduction: after the world ends, again. In: GURR, Barbara (ed.). Race, gender, and sexuality in post-apocalyptic TV and film. Nova Iorque: Palgrave MacMillan, 2015.

KRISTEVA, Julia. Estrangeiros para nós mesmos. Tradução de Maria Carlota Carvalho Gomes. Rio de Janeiro: Rocco, 1994.

MBEMBE, Achille. Necropolítica. Santa Cruz de Tenerife: Editorial Melusina, 2011.

MILLER, Frank. Holy Terror: terror sagrado. Barueri: Panini Books, 2013.

MORE, Thomas. Utopia. Tradução de Anah de Melo Franco. Prefácio de João Almino. Brasília: Editora da UnB, 2004.

PECEQUILO, Cristina Soreanu. As faces e conseqüências do terror: de 11/09 à doutrina bush. Ideias, Campinas, v. 2, n. 10, p. 55-82, dez. 2003. 
SANTOS, Boaventura de Sousa. Para além do pensamento abissal: das linhas globais a uma ecologia de saberes. Novos Estudos, São Paulo, n. 79, p. 71-94, nov. 2007.

SILVA, Tomaz Tadeu da. A produção social da identidade e da diferença. In: SILVA, Tomaz Tadeu da (org.). Identidade e diferença: a perspectiva dos Estudos Culturais. Petrópolis: Vozes, 2000. p. 73-102.

SONTAG, Susan. Ao mesmo tempo. São Paulo: Companhia das Letras, 2008.

Artigo enviado em: 10/05/2021. Aprovado em: 21/06/2021. 